\title{
Assessment of Contributions of the Methodology for the Construction of a Catalog of Information Technology Services Aimed at Public Entities
}

Cristian Mera Macías, Universidad Laica Eloy Alfaro de Manabí, Ecuador

Igor Aguilar-Alonso, Universidad Nacional Mayor de San Marcos, Peru

\begin{abstract}
Several field studies have shown low levels of implementation of this type of catalog in organizations in various countries around the world, which is accentuated in public organizations. To address this problem, the main objective of this research is to demonstrate the contribution of a methodology for the construction of a catalog of information technology services in the management of technology services aimed at public entities, which is tested and assessed in terms of its levels of contribution to the information management of technology services. The methodology used in this research was tested and evaluated by 46 IT professionals working in public organizations in Ecuador, verifying the contribution levels of the proposal in four aspects: 1) the identification of information technology services, 2) the classification of information technology services, 3) feedback from the service catalog as a transversal component, and 4) the automation of all the processes described. Favourable results were obtained regarding the proposed methodology.
\end{abstract}

\section{KEYWORDS}

IT Services, IT Services Catalog, IT Services Management, Machine Learning

\section{INTRODUCTION}

Public sector organizations financed by public resources exist to achieve outcomes that benefit the society (Baporikar \& Randa, 2020). According to Ishola \& Olusoji (2020), services promote the growth of organizations, driven by the dynamic nature of information and communication technologies. Service organizations today are engaging in continuous search of strategies to improve their service performance as well as deliver excellence customer-centric services (Ibrahim et al., 2018), since, the main function of the government sector is to provide services to the public based on the needs of the people (Galli, 2020). For this reason, many medium- and large-sized organizations have areas or departments dedicated to Information Technology (IT), which provide assistance to other departments of the organization in technological aspects. Each request made to an IT department is framed within an IT service (ITS), as an ITS uses IT in order to enable and optimize the organization's business processes (Pilorget \& Schell, 2018). ITS Management (ITSM) is a process-based approach which serves to strategically manage ITS throughout their life cycle (Trusson et al., 2014), involving the delivery and support of technology, applications, information, and training within an organization. 
Therefore, following ISTM guidelines provides organizations with greater chances of success in the activities carried out by their IT departments at the service management level.

One of the recommended practices in ITSM is the implementation of a catalog of information technology services (ITSC), which should be considered as a knowledge management system and which provides information about ITS to clients and service providers (Schorr \& Hvam, 2018), containing specifications of all the ITS that the organization needs to function properly (Hunnebeck, 2011).

The implementation of an ITSC is a recommended practice to develop a correct ITSM; however, it has been statistically demonstrated that there are low levels of ITSC implementation in many organizations. For example, in a study by Marrone et al. (2014), the levels of adoption of some processes of the ITSM defined in the Information Technology Infrastructure Library (ITIL) were examined, based on a survey applied in the United Kingdom, the United States, Australia, and in countries that speak German. One of the processes addressed was the ITSC, specifically regarding the management of the ITSC (ITSCM), where it was demonstrated that the adoption of the ITSCM only began starting with ITIL v3; however, the average adoption of this process in the countries studied was barely $23.6 \%$, a fairly low percentage (Marrone et al., 2014). Another study was carried out on the ITIL processes applied in organizations in countries such as Spain, Ecuador, Chile, Luxembourg, Colombia, Norway, Venezuela, and El Salvador, based on 40 surveys. It was evident that only $17.5 \%$ of the participants stated that they worked with ITSCM; again, a fairly low percentage (Lema et al., 2015).

In 2017, Iden and Eikebrokk published a study on the adoption of ITSM in Nordic countries (i.e., Sweden, Denmark, Finland, and Norway) based on 836 surveys, which detailed important results around ITSC implementation levels and showed interesting data; for example, the average level of adoption of ITSCM in the public sector was substantially lower than in the private sector $(21.9 \%$ versus $26.4 \%$ ) and, in general, the level of adoption of ITSCM in all types of organizations hardly changed from 2010 to 2014 (Iden \& Eikebrokk, 2017).

These results are in addition to a recent study applied to institutions in the Republic of Ecuador where, based on a survey applied to 45 IT professionals working in 22 public institutions, it was evident that only $7 \%$ of respondents stated that they had fully implemented ITSC and $22 \%$ reported having it partially implemented (Mera et al., 2018). In this investigation, it was also determined that two of the most important factors for the absence of an ITSC were ignorance of the subject and the regulations allowing its correct construction and subsequent management.

Faced with this problematic situation, considering the need to make and verify proposals for the construction and feedback of ITSCs (Mera \& Aguilar, 2018a) —even more so when few of the proposals made have been applied in public organizations (Mera \& Aguilar, 2019) — this was the justification to propose this research.

The main objective of this research is to show the contribution of the methodology for the construction of a catalog of information technology services in the management of technological services aimed at public entities, called ITSCCM, which was tested for IT professionals to assess its level of contribution to ITSM.

Regarding the methodology of this research, assessment of the ITSCCM was carried out by considering the activities in the ITSC architecture, which involve the identification of ITS, classification of ITS, feedback of the ITSC (which includes the withdrawal of ITS), and a transversal component (automation); this is all part of ITSCM. For this reason, four hypotheses are proposed in this research work, which are detailed in Section 4. To verify these hypotheses, 46 professionals working in public entities of the Republic of Ecuador were considered and we applied a survey before using the ITSCCM (i.e., evaluating the way in which they built the ITSC conventionally), followed by another survey after familiarization with and using the ITSCCM for the construction of an ITSC (i.e., a pre-test and a post-test), in order to determine the contribution of the ITSCCM.

This study is structured as follows: Section 2 contains the background, discussing the work previously carried out related to the construction of ITSCs. Section 3 details the conceptual framework, 
which defines the main concepts involved in the research. Section 4 shows the methodology, specifying the approach of the hypotheses and the evaluation of the proposal. Section 5 details the components of the ITSCCM, as well as its processes and sub-processes. Section 6 presents the evaluation of the proposal and the verification of the hypotheses raised in the research. Section 7 details the limitations of the study. In Section 8, the discussion is presented. Finally, our conclusions are drawn in Section 9.

\section{BACKGROUND}

Regarding the construction of ITSCs, there are several proposals that have been developed:

In 2005, Anders developed a generic model for an ITSC. With this model, software was built using Java as a development platform and MySql as database, based on the range of ITS that were available at that time; however, this model was not applied in public organizations.

In 2009, Lyons developed an ITSC that focused on the needs of clients, considering the implementation guidelines of the ITIL framework. As a product of the work, an ITSC was obtained which resulted in a dynamic functional website for the private universities Hobart and William Smith. In that same year, Mazvimavi and Benyon developed a theoretical model which brought together the ideas and problems identified in the related literature on ITSC; however, their model was not tested in the real world.

In 2010, Mendes and Da Silva proposed solutions to improve the definition of the service, components, the roles of those involved in its management, and the life cycle of ITS. This proposal was implemented only in a private organization, where their ITS were identified and their ITSC was established. Then, Dan Xu et al. (2010) proposed a method of service composition using servicebased service selection and service-level-based (SL) service composition. For these researchers, there were a number of issues that needed further study which the authors recommended addressing in the future to manage and innovate ITS. The viability of their method was evaluated by simulation experiments. Likewise, Arnaut et al. (2010) proposed an ontology for service-oriented architectures (SOA) with an emphasis on the implementation of a catalog in the development phase. This study was not tested in public organizations and did not include machine learning (ML).

Ribeiro et al. (2011) carried out an investigation whose main objective was to create a catalog with the possibility of automating the availability of services in an IT infrastructure, aligning virtualization concepts and infrastructure management tools. This study was not tested in public organizations.

Then, Rosa et al. (2012) proposed a method for service identification (SIM) using incidents based on an ITS Reference Catalog (ITSRC). Their study included an analysis of incidents to determine which ITS they correspond to; it should be noted that this was one of the few proposals which was applied in public organizations. Likewise, Mendes et al. (2012) proposed a method based on the design and engineering for organizations (DEMO) methodology to identify ITS; however, the method was not applied in public organizations and, according to the authors, it should be applied in more complex situations than the one initially used to evaluate the method. Then, Arcilla et al. (2012) proposed a model based on the concept of an asset process library which allows micro-, small-, or medium-sized companies to build their ITSC in a simple, flexible, and economic way. This work was related to another published one year later that, although the case study obtained successful results, additional experiments must be carried out to add validity to the proposed model, in the sense of improving the coverage of the ITSC process (Arcilla et al., 2013).

Gama et al. (2013) proposed an ITSRC to resolve the lack of a base for starting an ITSC. This proposal was applied in the public sector but did not include any automation.

In 2015, Meister and Jetschni described a project to develop a semantic web-based ITSC at a public university in Germany. However, as a long-term goal, the researchers pointed to the implementation of ITSCs based on semantic web technologies in other universities or public organizations in the Federal State of Brandenburg. 
In 2016, Sembiring and Surendro proposed a model that describes how to make an ITSC which can be adopted by an organization. However, at a later stage, this ITSC implementation model needs to be verified and validated in a real organization.

In 2017, Rugg worked to develop a unified ITSC representing ITS provided by more than 50 ITS providers across an organization's campus, with the goal of increasing internal and external transparency, allowing the institution to identify redundant services. For this purpose, they defined a methodology for data collection, designed the user interface, conducted usability studies, and developed a roadmap to maintain the ITSC for years to come.

In 2018, Schorr and Hvam explored the use of design science methods to define and evaluate the requirements for ITSC information content. However, although they provided initial results, the researchers indicated that the proposed method should be tested during other ITSC implementation projects, in order to generalize it.

In 2019, Mera and Aguilar made a proposal for the identification of ITS in public organizations, which included the identification and classification of ITS to form the ITSC. This was achieved using ML as a cross-cutting component for construction of the ITSC. This proposal was verified in a public organization and was evaluated by applying the quality factors of Moody for the evaluation of artefacts that serve to build the ITSC (Moody et al., 2003).

Mera et al. (2020) proposed a method for feedback from an ITSC, which embraced the automation principles considered in a previous work (Mera \& Aguilar, 2019); therefore, this work is complementary, allowing the formation of the ITSCCM assessed in this study.

\section{CONCEPTUAL FRAMEWORK}

\subsection{Building The It Services Catalog}

The ITSC is a fundamental component of the IT services portfolio (ITSP) (Hunnebeck, 2011), which describes the characteristics, components, and charges, among other aspects, of the services specified in the catalog (Mazvimavi \& Benyon, 2009). The ITSC plays a key role in the documentation and management of services in the organization; in addition, ITSCs provide the ability to reduce the cost of IT support and decrease manual intervention, which should be done through automated workflows (O’Loughlin, 2009).

An ITSC must include information related to the catalog and information related to each of the services; that is, the part of the catalog that details the general information of the catalog, the profile of the catalog, and the classification characteristics of the catalog, along with the part of the service which describes the characteristics of the service (e.g., general information, SL parameters, category, and so on) (D. Xu et al., 2010). Figure 1 shows part of a standard ITSC, where the ITSC is a structure that has two preponderant elements: category and service.

To build an ITSC, it is necessary to have clear practices which allow specification of the most appropriate ITS, depending on the organization (Mazvimavi \& Benyon, 2009). One of the most important activities to build an ITSC is the identification of ITS, which goes hand in hand with ITS classification (Mera \& Aguilar, 2019).

Other important activities are the feedback from the ITSC and the withdrawal of ITS that are no longer necessary to keep in the ITSC (Mera \& Aguilar, 2018a); this is at the level of the architecture of the catalog itself. There are other activities within the construction of the ITSC, such as carrying out projects for the implementation of the ITSC, obtaining support for its management, and developing service level agreements (SLA), among other activities.

\subsubsection{ITS Identification}

According to Hunnebeck (2011), there are five important aspects in the design of services; among these are the systems and tools of service management, especially the service portfolio (including the 


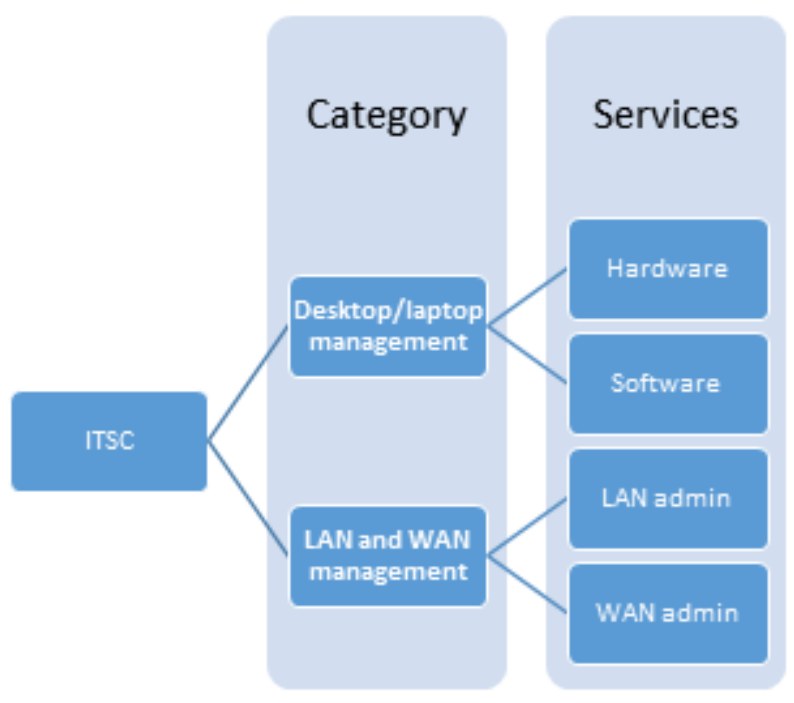

ITSC). One of its activities is the identification of ITS which, according to Huergo et al. (2014), is one of the main challenges for SOA adoption, which aims to determine which services are appropriate to implement.

At a general level, in service engineering, the identification of services plays a fundamental role, as it establishes the basis for subsequent processes (Rong et al., 2014). Identification of ITS is one of the most important activities in the construction process of the ITSC and also of the ITSCM; in fact, several studies have focused on this topic (Mera \& Aguilar, 2019). The identification of ITS is one of the activities of the service life cycle (Fischbach et al., 2013), which can be carried out in different ways.

To identify services, the business requirements must be analyzed which, in the IT field, can be provided by IT workers and IT users. The services that IT users need can be extracted from requests made or incidents logged by IT users in their daily work (Kalia et al., 2017); therefore, it is necessary to analyze each request to extract the keywords that allow for identification of the services required by IT users.

The services that can be identified and used to build an ITSC can be related to Hardware, Software, LAN administration, WAN administration, VPN connections, firewall services, and antivirus services, among others (Gama et al., 2013).

\subsubsection{ITS Classification}

Once the ITS have been identified, it is necessary to classify them. To carry out this task, an ITSRC is generally used (Gama et al., 2013), which is a structure made up of categories and services that serve as a template to create other ITSCs (Magdalena Arcilla et al., 2013).

The idea is to compare the identified services with the services that the ITSRC has, such that the services that do not appear in said reference catalog are discarded, and those that do appear are considered in the new ITSC (M. Arcilla et al., 2012), together with the categories in which the services belongs.

The categories that ITS can be grouped into include Desktop and Laptop Management, LAN and WAN Management, Email and Messaging, Security Management, Accounts and Passwords, 
and Equipment Management, among others (Mera \& Aguilar, 2019). These categories may vary, depending on the ITSRC that is used for the ITS classification process.

\subsubsection{ITSC Feedback}

The ITIL version 4 service value chain provides an operating model for the creation, delivery, and continuous improvement of services (AXELOS, 2019). Furthermore, one of the components of the service value system proposed by ITIL is continuous improvement; therefore, the ITSC that is part of the ITSM cannot be an exception.

One of the most important objectives of the ITSCM process is guaranteeing that a catalog containing accurate information on ITS is produced and maintained (Lloyd \& Rudd, 2007). In order to maintain the ITSC, it is necessary to confirm the services that are being used and discard the services that are no longer being used.

During the useful life of the ITSC, it is possible that new services are added to the catalog. For this, one of the mechanisms that can be used is the analysis of requests or incidents supplied by IT users, with the aim of identifying the service and its corresponding category within the ITSC; although many requests may lead to the creation of new services to be included within the ITSC.

\subsubsection{ITSM and Automation}

One of the great challenges in IT management in organizations is the simplification and automation of management tasks at a general level (Graupner et al., 2006). For ITSM, the main focus is not on the development of IT applications, but on technology services management (Marrone \& Kolbe, 2011), which has evolved as an essential part of IT management.

ITSM provides a methodical approach to "IT service management", from design, implementation, and operation to continuous improvement. Some studies have linked ITSM with a comprehensive framework including four key components: the ITSP, the ITSC, the processed services, and the configuration management database (CMDB) (Pilorget \& Schell, 2018).

At the ITSM automation level, it has become increasingly common to use requests from IT users as an input to determine the ITS specified in the ITSC, as well as also to understand which of those services they need at a certain moment. For this, it is necessary to apply techniques, methods, or any mechanism derived from artificial intelligence (AI), since AI-based systems have become the main strategic trend in the technological area (Trad, 2021). Thanks to this, at present, it is possible to automatically process the requirements that the ITS requested by clients in contracts (i.e., long and detailed documents) must meet (Motahari-Nezhad et al., 2016). It is also possible to perform language identification and translation; extract hierarchical themes, entities, and their most frequent relationships; summarize text; and extract feelings and knowledge from unstructured text data using natural language processing techniques from requests or tickets (Ali, 2018). Furthermore, the identification and classification of ITS can be carried out for the conformation of the ITSC from a history of requests (specified in natural language) of the IT users in a certain organization (Mera \& Aguilar, 2019).

\subsection{Machine Learning or ML}

\subsubsection{Text Mining}

ML allows machines to learn from supplied data and build predictions without being explicitly programmed for that task (Shahid et al., 2020); in other words, ML is a capability of the systems to acquire knowledge and improve automatically without programming the system and human assistance (Sangwan \& Bhatnagar, 2020). As mentioned above, ML has been included in various ITSM activities. As the ITSC has categories which, in turn, can contain various services, and as each service has characteristics that differentiates it from other services (Mazvimavi \& Benyon, 2009), 
we are considering a classification task. On the other hand, IT users are increasingly requesting ITS through the use of natural language expressed in text (Mera \& Aguilar, 2018b).

At present, one of the most widely used processes to analyze natural language is text mining, where one of its main tasks is to extract significant information from text or character strings. In the case of ITSM, at the level of request management, requests for incidents that come from IT users (often called tickets) may contain a lot of ambiguity, spelling errors, and grammatical errors, among the most common. In order to normalize these character strings, operations must be carried out on the text, such as those that are applied regularly in text mining, including the elimination of words, normalization of abbreviations, and conversion of characters to upper or lower case as appropriate, and so on (J. Xu et al., 2020).

The use of text mining not only applies to a small string of characters, but extends to the analysis of one or more documents in the search for patterns, which allows for determination of the main ideas of the analyzed documents, based on natural language analysis and processing. This is one of the main activities of large corporations, such as IBM (Megahed et al., 2020), where analysis extends to understanding what the customer needs and understanding the text in various languages, to name two examples.

\subsubsection{Classification Systems}

To implement ML, there are several approaches, tools, models, techniques, algorithms, and so on; among these are multiclass classification systems. For our purposes, we find several options in this category, which are briefly explained below.

The maximum entropy approach has been widely studied in applied statistics, the principle of which establishes that the probability distribution that best represents the current state of knowledge is the one with the highest entropy; it can also be defined as an inference method to obtain the results in the context of statistical mechanics, being ideal in cases where complete information is necessary for a detailed description that is lost or not available (Camiola et al., 2020).

Another option that can be used for classification systems is the averaged perceptron, which is characterized as being a basic version of a neural network, where the inputs are classified into several possible outputs based on a linear function, which are then combined with a set of weights that are derived from the feature vector; this is why it is called a perceptron (Rajagopal et al., 2020).

Another alternative to build a classification system is the stochastic gradient descent approach, which is characterized by being simple and efficient. It has been successfully applied in ml problems, specifically in text classification and natural language processing. In deep neural network training, this approach plays a key role in the optimization process and promotes the success of deep learning approaches. In the iteration of this approach, a sample is randomly selected and the loss function is optimized for the chosen sample (He et al., 2020).

Another option is the use of gradient increase decision trees, which consist of a ML technique that can perform regression analysis and is useful for statistical classification problems, with the aim of forming a predictive model in the form of a set. From prediction models, within an iteration, this technique applies decision trees, as carried out by adjusting the negative gradients. Despite this, with the development of large data sets, the levels of efficiency and precision of this method have certain difficulties (Khafajeh, 2020).

\subsection{The ITSC Management Process}

ITSCM is supported by activities such as managing, editing, and keeping the list of available services updated as they are introduced, changed, or withdrawn (AXELOS, 2019). Therefore, the objective of ITSCM is to provide a single source of consistent information on all agreed services, as well as to ensure that it is widely available to those who are approved to access them (Gama et al., 2013). There are several intrinsic activities in the ITSCM, such as service definition (related to ITS identification), interfaces and dependences between services, establishing a management framework, 
defining requirements for the ITSC, creating the ITS, publishing the ITSC, monitoring the ITSC, and withdrawal of services, among others.

\section{METHODS}

The methodology used in this research is structured as follows:

- Hypothesis statement

- Assessment of the proposal

\subsection{Hypothesis Statement}

The different perspectives and approaches to structuring an ITSC can be found in the literature, but the total number of works on this topic is relatively small (Nissen et al., 2015), which has been recently reaffirmed (Schorr \& Hvam, 2018). It is also necessary to consider that, at the level of proposals to build and manage an ITSC, little applied research has been done in public organizations. Furthermore, few works have included proposals using ML principles, such as those of Mera and Aguilar (2019) and Mera et al. (2020). As a result, in the research carried out, considering the results related to the ITSCCM obtained through previous case studies, where its components were tested, it was necessary to verify its level of contribution to ITSCM regarding the architecture of the ITSC, from the perspective of the IT professionals who work in public organizations.

To assess the contribution of the ITSCCM to ITSCM, the following hypotheses were proposed:

- HE1: The ITSCCM contributes to the process of identifying IT services.

- HE2: The ITSCCM contributes to the IT service classification process.

- HE3: The ITSCCM contributes to the feedback of the IT service catalogue.

- HE4: The ITSCCM contributes to the automation of IT services management

These hypotheses were structured using the following structure (Figure 2):

Figure 2. Elements for hypothesis formulation

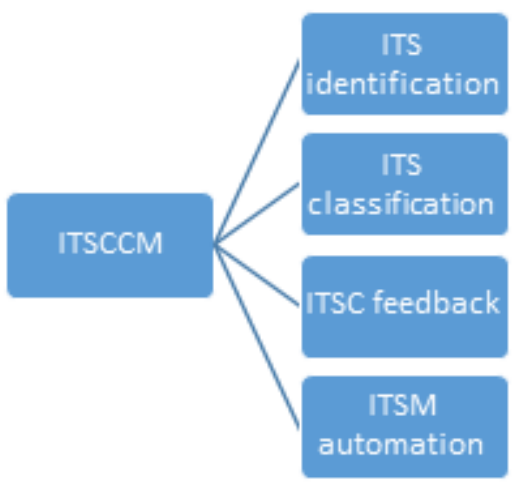




\subsection{Assessment Of the Proposal}

To assess the contribution of the ITSCCM to ITSCM, IT professionals working in the public sector were considered. We carried out an assessment of the way in which they carried out the activities of ITSCM before and after applying the ITSCCM. The professionals who were included in this study met the following characteristics:

- $\quad$ Analyst, Graduate, or Engineer (systems, IT, or related);

- Worked in the public sector; and

- Had knowledge of the ITSC

To carry out the evaluation process, a non-probability sampling technique was used, such as the network or snowball technique. The professionals initially chosen were asked to suggest other professionals to continue evaluating the tool provided. Finally, 46 professionals were selected in total.

The professionals who participated in the assessment are divided as follows: regarding sex, $76 \%$ of the participants were men, and $24 \%$ were women. In terms of experience, $24 \%$ of professionals have 1 to 3 years of experience, $48 \%$ have 4 to 10 years of experience, and $28 \%$ have more than 10 years of experience as an IT professional.

\subsubsection{Data Collection Techniques}

A duly validated questionnaire (Appendix A - Tables A.1 and A.2) was used as an instrument. The questionnaire was designed based on the hypotheses proposed in this study. In order for IT professionals to be able to answer the questions, it was necessary to create a blog, where the following were specified: the "before using the ITSCCM" questionnaire, an explanation of how the ITSCCM works, a link for them to use the ITSCCM (built like software), and the "after using the ITSCCM" questionnaire. To apply the questionnaire, the Google forms tool was used, as the IT professionals were from different parts of Ecuador.

\subsubsection{Validation Instrument}

Regarding the qualitative evaluation of the instrument, its content was evaluated by reviewing the available knowledge, approaching the population, and expert judgment. Regarding the reliability or consistency tests of the applied instrument, Cronbach's alpha was used which, according to Huanca (2018), is a statistical technique of internal consistency based on the average of the correlations of the items (1). With this method, the reliability of an instrument can be evaluated. The following parameters are generally accepted:

Alpha coefficient $>0.9$ corresponds to Excellent;

Alpha coefficient $>0.8$ corresponds to Good;

Alpha coefficient $>0.7$ corresponds to Acceptable;

Alpha coefficient $>0.6$ corresponds to Questionable;

Alpha coefficient $>0.5$ corresponds to Poor;

Alpha coefficient $<0.5$ corresponds to Unacceptable.

The Cronbach's alpha formula is as follows:

$r=K / K-1\left[1-\Sigma^{S I^{2}} / \Sigma S T^{2}\right]$

where

$K=$ Number of items,

$S I^{2}=$ Variance of the scores of each item,

$S T^{2}=$ Variance of total scores . 


\subsubsection{Data Normality Tests}

To check the normality of the data set, before choosing the appropriate test to check the hypothesis, the Shapiro-Wilk test was applied. As the data set that was analyzed for each of the hypotheses consisted of 46 records, according to Flores et al. (2019), the chosen test was the most powerful in evaluating its normality (2) (3) (4). The test statistic was calculated as follows:

$$
W=b^{2} / \Sigma_{i=1}^{n}\left(x_{i}-\bar{x}\right)^{2}
$$

where

$$
b=\sum_{i=1}^{n} a_{i}\left[X_{(n-i-1)}-x_{i}\right]
$$

and

$$
a_{i}=m^{\prime} V^{-1}\left(m^{\prime} V^{-1} m\right)^{-1 / 2}
$$

The successive differences obtained by subtracting the first value from the last value, the second from the antepenultimate, and so on, are the tabulated coefficients in the Shapiro table. Furthermore, $m$ $=\left(\mathrm{m}_{1}, \ldots ., \mathrm{m}_{\mathrm{n}}\right)$ are the mean values of the ordered statistics of independent and identically distributed random variables sampled from normal distributions, and $\mathrm{V}$ is the covariance matrix of these order statistics.

\subsubsection{Hypothesis Testing}

As the proposed work includes the participation of IT professionals - in particular, to assess the way in which they developed the ITSCM before using the ITSCCM and, then, another assessment after having used it-it is a related samples test (Rubio \& Berlanga, 2012). To carry out a hypothesis test in this case, the "Student's t-test for related samples" should be used when the distribution of the data is normal, as this test requires at least two variables that represent the values of the pre-test and post-test, where numerical variables are considered (5). The formula to calculate the parameter t for related samples is as follows:

$$
t=\bar{D}-\mu D /(S D / \sqrt{n})
$$

where

$\mathrm{t}=$ Student $\mathrm{s}^{\mathrm{s}}$ statistic for related samples,

$\bar{D}=$ difference between the averages of the two measurements,

$\mu D=$ average difference between population means,

$S D=$ standard deviation of the differences between the two measurements,

$n=$ sample size.

On the other hand, when the distribution of the data is not normal, it is advisable to use the Wilcoxon signed rank test, which is a non-parametric test that compares the mean range of two related samples and determines whether there is a difference between them. To apply the test, the absolute values of the differences in the performance of two algorithms are calculated for each instance and 
ordered from highest to lowest. Then, the places that the differences occupy in favor of one or the other classifier are compared (Jimenez et al., 2018) (6). Its statistic is calculated as follows:

$w=\sum_{K=m+1}^{m+n} \Re_{K}$

where

$R_{K}=$ The range of $Y_{k}$ in the combined sample,

$=j$ si $Y_{k}=Z_{j} y 1 \leq j \leq m+n$

It follows that, when the value $\mathrm{W}$ is less than 0.05 , there is a difference and, therefore, the null hypothesis is rejected and the investigator's hypothesis is accepted.

\subsubsection{Software Used for The Statistical Process}

The software used to perform the tabulation, data analysis, and to carry out the different tests for testing the hypotheses was IBM SPSS Statistics.

\section{METHODOLOGY FOR THE CONSTRUCTION OF THE CATALOG OF INFORMATION TECHNOLOGY SERVICES OR ITSCCM}

The ITSCCM is based on the ITSM best practices contained in current standards, as well as on various works previously carried out in this area, with the aim of facilitating the construction and management of an ITSC in public entities considering four fundamental aspects: ITS identification, ITS classification, ITSC feedback, and automation of the mentioned processes. The ITSCCM contains a "learning" phase where, through the "knowledge" acquired from the good ITSCM of four public entities, a process was developed which allows the construction and management of an ITSC automatically from the history of requests and resolutions. The second phase consists of the automatic construction and management of the ITSC, as shown in Figure 3.

Figure 3 shows the structure of the ITSCCM: Phase 1 includes the extraction and appropriation of knowledge, which have been explained in detail previously; Phase 2 includes the identification of ITSs and their classification, which have also been explained (Mera \& Aguilar, 2019). In this case, the mechanism that is highlighted with another color in Figure 3 is "ITSC feedback and withdrawal of services", which was added based on the principles proposed by Mera et al. (2020), as a continuation of their investigation. The proposal was verified through case studies in public organizations in Ecuador, applying Moody's quality factors for the evaluation of artifacts that are used for the construction of the ITSC.

The ITSCCM consists of several processes and, within them, several sub-processes. Figure 4 shows the processes of Phase 1 concerning the construction of the solution including automation as a cross-sectional element.

In Figure 5, the processes of Phase 2 of the ITSCCM concerning the construction and management of the ITSC are shown, including automation as a transversal element.

In order for IT professionals to test the methodology, a software tool was built based on the processes indicated in Figures 3, 4 and 5.

From the selection of the "origin of knowledge" databases, the construction of the single ITSRC, the creation of the structure and the transfer of requests to the created structure, we obtained the database called "knowledge", with a table called "messages" that includes the SERVICE and 
Figure 3. Structure of the ITSCCM

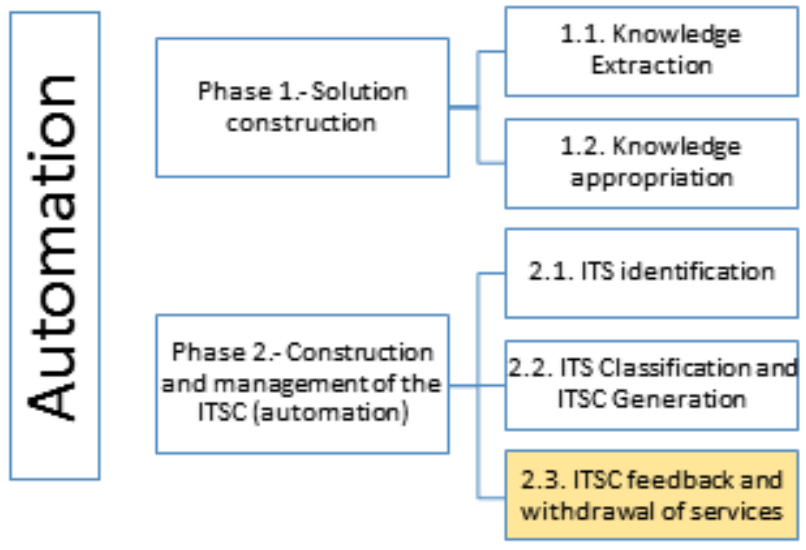

Figure 4. Processes of Phase 1 of the ITSCCM

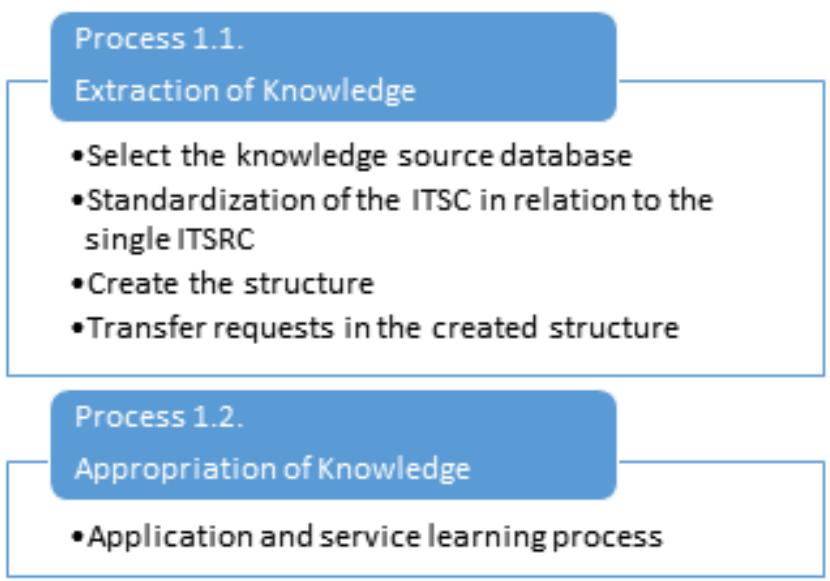

REQUEST fields, which stores the knowledge that was used to learn the application. To carry out this activity, we worked with requests in the Spanish language. 
Figure 5. Processes of Phase 2 of the ITSCCM

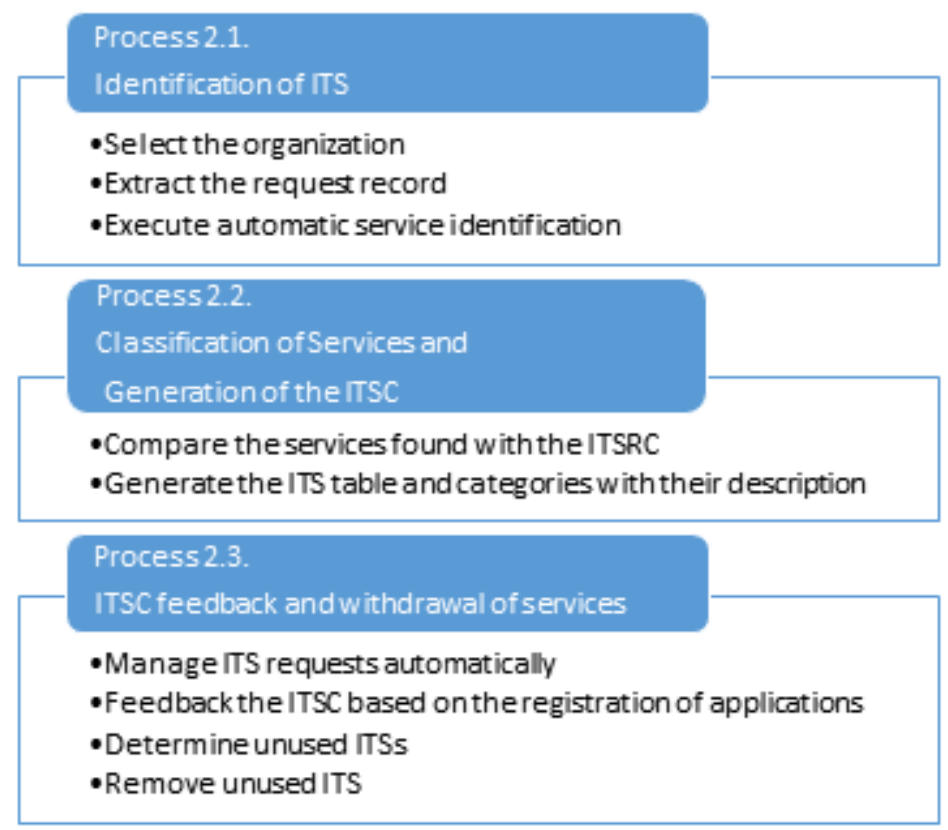

Then a module was applied that applies ML to learn from the knowledge stored in the structure. Based on the ML.NET model Builder tool, the "Issue Classification" option was used to carry out the learning process, the model training was carried out for 120 seconds, from this process we obtained an overall precision of $95.24 \%$ achieved by the algorithm "SdcaMaximumEntropyMulti", this algorithm outperformed: "AveragedPerceptronsOva" with 94.41\%, "SymbolicSgdLogistincTegressionOva" with $91.81 \%$ and "LightGbmMulti" with $91.07 \%$ (Figure 6).

Then an application was built so that IT professionals could download it and make the corresponding assessment.

\section{Figure 6. Statistics of tested algorithms}

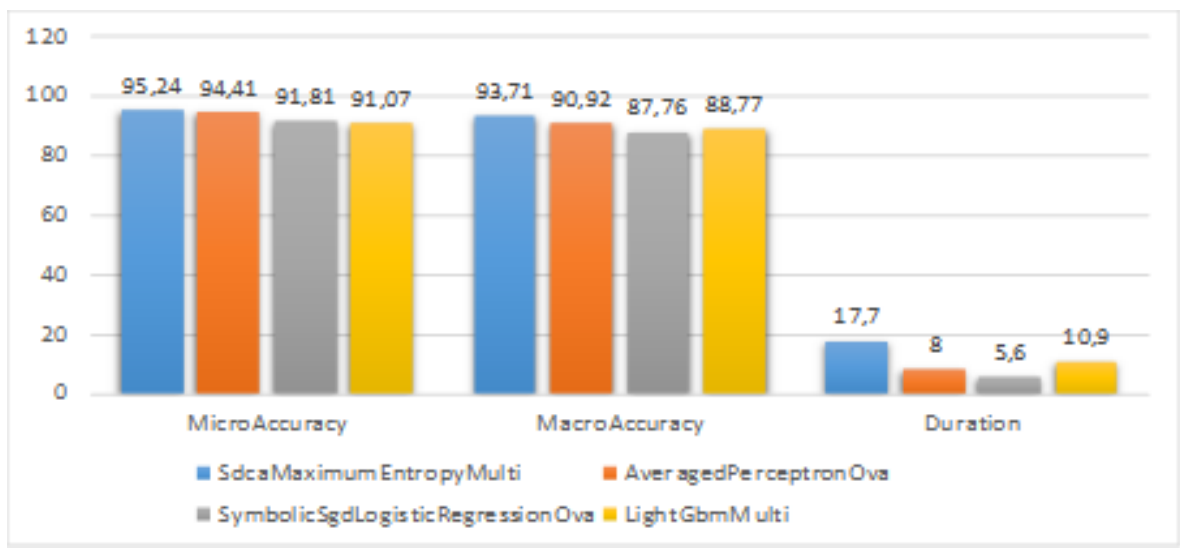


Table 1. Summation of ITS identification items, before and after

\begin{tabular}{|l|l|l|}
\hline \multicolumn{2}{|c|}{} & \multicolumn{2}{|l|}{ SUM OF ITEMS } \\
\cline { 2 - 3 } & $\begin{array}{l}\text { BEFORE } \\
\text { (with previous mechanisms) }\end{array}$ & $\begin{array}{l}\text { AFTER } \\
\text { (utilizing the ITSCCM) }\end{array}$ \\
\hline TOTAL & 628 & 855 \\
\hline MEAN & 13.65 & 18.59 \\
\hline VARIANCE & 5.832 & 6.559 \\
\hline
\end{tabular}

\section{ASSESSMENT OF THE PROPOSAL AND HYPOTHESIS TESTING}

To check the level of contribution of the ITSCCM in ITSCM, it was necessary to pose the hypotheses described in Section 4.1.

Statistical calculations to validate the hypotheses were performed for the identification of ITS, classification of ITS, feedback from ITSC, and automation of ITSM, using Student's t-tests for related samples in the case of normal distributions, and the Wilcoxon signed rank test for distributions that were not normal. These tests were used in order to discern whether there was an increase or decrease in values in the same group studied; in this case, these tests were chosen because the reference value that was considered was a sum of items, giving a numerical result (i.e., the total sum of items was worked on before using the ITSCCM and after using it for the activities described above).

Regarding the tests to determine whether the data distribution was normal, in each hypothesis, the difference between the sum of items was calculated and the Shapiro-Wilk test was applied to this difference, as there were 46 items that were examined (Source data, Appendix B).

\subsection{ITS Identification}

\subsubsection{Hypothesis Formulation}

The hypotheses proposed for the identification of ITS were the following:

- $\quad \mathrm{H} 1_{1}$. The ITSCCM contributes to the process of identifying IT services

- $\quad \mathrm{H} 1_{0}$. The ITSCCM does not contribute to the process of identifying IT services

\subsubsection{Data (items $1,2,3$, and 4 of Appendix B)}

\subsubsection{Level of Significance}

A standard significance level of $5 \%$ was used (i.e., $\mathrm{p}<0.05$ was considered significant).

\subsubsection{Normal Distribution Check}

To check if the data were normally distributed, the Shapiro-Wilk test was applied to the difference between the "sum of items before" and the "sum of items after", obtaining the following results (Table 2).

According to Table 2, the value of the asymptotic significance was 0.006 , much less than 0.05 ; therefore, to estimate the p-value to perform the corresponding hypothesis test, the Wilcoxon signed rank test was applied.

\subsubsection{P-Value Estimation}

When applying the Wilcoxon test, the following results were obtained: 
Table 2. Normality test, ITS identification

\begin{tabular}{|l|l|l|}
\hline \multicolumn{2}{|l|}{ Shapiro Wilk } & Sf \\
\hline Statistical & Df \\
\hline .926 & .46 & .006 \\
\hline
\end{tabular}

\subsubsection{Decision making}

Based on the results shown in Tables 3 and 4, the ultimate value was below the significance level $(\mathrm{p}<0.05)$. Therefore, hypothesis $\mathrm{H} 1_{0}$ was rejected and hypothesis $\mathrm{H} 1_{1}$ was accepted. Therefore, the following can be stated:

The ITSCCM contributes to the process of identifying IT services.

Table 3. Its identification ranges

\begin{tabular}{|l|l|l|l|l|}
\hline \multicolumn{2}{|c|}{} & N & Average range & Sum of ranges \\
\hline \multirow{3}{*}{$\begin{array}{l}\text { Total_After - Total_ } \\
\text { Before }\end{array}$} & Negative ranges & $1^{\mathrm{a}}$ & 32.00 & 32.00 \\
\cline { 2 - 5 } & Positive ranges & $43^{\mathrm{b}}$ & 22.28 & 958.00 \\
\cline { 2 - 5 } & Draws & $2^{\mathrm{c}}$ & & \\
\cline { 2 - 5 } & Total & 46 & & \\
\hline
\end{tabular}

a. Total_After < Total_Before

b. Total_After $>$ Total_Before

c. Total_After $=$ Total_Before

Table 4. ITS identification test statistics

\begin{tabular}{|l|l|}
\hline & Total_After - Total_Before \\
\hline $\mathrm{Z}$ & $-5.419^{\mathrm{b}}$ \\
\hline Asymptotic significance (bilateral) & .000 \\
\hline
\end{tabular}

a. Wilcoxon signed rank test

b. Based on negative ranges

$p=0.000000059947$

\subsection{ITS Classification}

\subsubsection{Hypothesis Formulation}

The hypotheses proposed for the classification of ITS were the following:

- $\quad \mathrm{H} 2{ }_{1}$. The ITSCCM contributes to the IT service classification process

- $\quad \mathrm{H} 2_{0}$. The ITSCCM does not contribute to the IT service classification process 
Table 5. Summation of ITS classification items, before and after

\begin{tabular}{|l|l|l|}
\hline \multicolumn{2}{|c|}{} & \multicolumn{2}{|l|}{ SUM OF ITEMS } \\
\cline { 2 - 3 } & $\begin{array}{l}\text { BEFORE } \\
\text { (with previous mechanisms) }\end{array}$ & $\begin{array}{l}\text { BEFORE } \\
\text { (with previous mechanisms) }\end{array}$ \\
\hline TOTAL & 672 & 856 \\
\hline MEAN & 14.61 & 18.61 \\
\hline VARIANCE & 5.977 & 6.910 \\
\hline
\end{tabular}

\subsubsection{Data (items 5, 6, 7, and 8 of Appendix B)}

\subsubsection{Level of Significance}

A standard significance level of $5 \%$ was used (i.e., $\mathrm{p}<0.05$ ).

\subsubsection{Normal Distribution Check}

To check if the data were normally distributed, the Shapiro-Wilk test was applied to the difference between the "sum of items before" and the "sum of items after", obtaining the following result (Table $6)$.

According to Table 6 , the value of the asymptotic significance was 0.007 , less than 0.05 . Therefore, to estimate the p-value and perform the corresponding hypothesis test, the Wilcoxon signed rank test was applied.

Table 6. Normality test, ITS classification

\begin{tabular}{|l|l|l|}
\hline \multicolumn{2}{|l|}{ Shapiro Wilk } & \multicolumn{2}{l|}{} \\
\hline Statistical & Df & Sig. \\
\hline .928 & .46 & .007 \\
\hline
\end{tabular}

\subsubsection{P-Value Estimation}

When applying the Wilcoxon test, the following results were obtained:

\subsubsection{Decision Making}

Based on the results shown in Tables 7 and 8, the ultimate value was below the significance level $(\mathrm{p}<0.05)$. Therefore, hypothesis $\mathrm{H} 2{ }_{0}$ was rejected and hypothesis $\mathrm{H} 2{ }_{1}$ was accepted. Therefore, the following can be stated:

The ITSCCM contributes to the IT service classification process.

\subsection{ITSC Feedback}

\subsubsection{Hypothesis Formulation}

The hypotheses proposed for the classification of ITS were the following:

- $\quad \mathrm{H} 3_{1}$. The ITSCCM contributes to the feedback of the IT service catalogue

- $\mathrm{H}_{0}$. The ITSCCM does not contribute to the feedback of the IT service catalogue 
Table 7. ITS classification ranges

\begin{tabular}{|l|l|l|l|l|}
\hline \multicolumn{2}{|c|}{} & N & Average range & $\begin{array}{l}\text { Sum of } \\
\text { ranges }\end{array}$ \\
\hline \multirow{3}{*}{$\begin{array}{l}\text { Total_After - Total_ } \\
\text { Before }\end{array}$} & Negative ranges & $4^{\text {a }}$ & $\mathbf{1 0 . 3 8}$ & $\mathbf{4 1 . 5 0}$ \\
\cline { 2 - 6 } & Positive ranges & $39^{\mathrm{b}}$ & 23.19 & 904.50 \\
\cline { 2 - 6 } & Draws & $3^{\mathrm{c}}$ & & \\
\cline { 2 - 5 } & Total & 46 & & \\
\hline
\end{tabular}

a. Total_After < Total_Before

b. Total_After > Total_Before

c. Total_After $=$ Total_Before

Table 8. ITS classification test statistics

\begin{tabular}{|l|l|}
\hline & Total_After - Total_Before \\
\hline $\mathrm{Z}$ & $-5.225^{\mathrm{b}}$ \\
\hline Asymptotic significance (bilateral) & .000 \\
\hline
\end{tabular}

a. Wilcoxon signed rank test

b. It is based on negative ranges

$p=0.00000017399$

Table 9. Summation of ITSC feedback items, before and after

\begin{tabular}{|l|l|l|}
\hline \multirow{2}{*}{} & \multicolumn{2}{|l|}{ SUM OF ITEMS } \\
\cline { 2 - 3 } & $\begin{array}{l}\text { BEFORE } \\
\text { (with previous mechanisms) }\end{array}$ & $\begin{array}{l}\text { BEFORE } \\
\text { (with previous mechanisms) }\end{array}$ \\
\hline TOTAL & 570 & 854 \\
\hline MEAN & 12.39 & 18.57 \\
\hline VARIANCE & 10.643 & 6.918 \\
\hline
\end{tabular}

\subsubsection{Data (items 9, 10, 11 , and 12 of Appendix B)}

\subsubsection{Level of Significance}

A standard significance level of $5 \%$ was used (i.e., $\mathrm{p}<0.05$ ).

\subsubsection{Normal Distribution Check}

To check if the data were normally distributed, the Shapiro-Wilk test was applied to the difference between the "sum of items before" and the "sum of items after", obtaining the following result (Table 10).

According to Table 10, the value of the asymptotic significance was 0.037 , less than 0.05 . Therefore, to estimate the p-value and perform the corresponding hypothesis test, the Wilcoxon signed rank test was applied.

\subsubsection{P-value Estimation}

When applying the Wilcoxon test, the following results were obtained: 
Table 10. Normality test, ITSC feedback

\begin{tabular}{|l|l|l|}
\hline \multicolumn{2}{|l|}{ Shapiro Wilk } & Sig. \\
\hline Statistical & Df & .037 \\
\hline .947 & .46 & \\
\hline
\end{tabular}

\subsubsection{Decision Making}

Based on the results shown in Tables 11 and 12, the ultimate value was below the significance level $(\mathrm{p}<0.05)$. Therefore, hypothesis $\mathrm{H} 3_{0}$ was rejected and hypothesis $\mathrm{H} 3_{1}$ was accepted. Therefore, the following can be stated:

The ITSCCM contributes to the feedback of the catalog of IT services.

\section{Table 11. ITSC feedback ranges}

\begin{tabular}{|l|l|l|l|l|}
\hline \multicolumn{2}{|c|}{} & N & Average range & Sum of ranges \\
\hline \multirow{3}{*}{\begin{tabular}{l} 
Total_After - Total_ $\begin{array}{l}\text { Before } \\
\end{array}$ \\
\cline { 2 - 5 }
\end{tabular}} & Negative ranges & $1^{\mathrm{a}}$ & 25.00 & 25.00 \\
\cline { 2 - 5 } & Positive ranges & $44^{\mathrm{b}}$ & 22.95 & 1010.00 \\
\cline { 2 - 5 } & Draws & $1^{\mathrm{c}}$ & & \\
\cline { 2 - 5 } & Total & 46 & & \\
\hline
\end{tabular}

a. Total_After <Total_Before

b. Total_After $>$ Total_Before

c. Total_After =Total_Before

\section{Table 12. ITSC feedback test statistics}

\begin{tabular}{|l|l|}
\hline & Total_After - Total_Before \\
\hline $\mathrm{Z}$ & $-5.570^{\mathrm{b}}$ \\
\hline Asymptotic significance (bilateral) & .000 \\
\hline
\end{tabular}

a. Wilcoxon signed rank test

b. It is based on negative ranges

$p=0.00000002554$

\subsection{ITS Management Automation}

\subsubsection{Hypothesis Formulation}

The hypotheses proposed for the automation of ITS management were the following:

- $\mathrm{H}_{1}$. The ITSCCM contributes to the automation of the management of IT services.

- $\quad \mathrm{H} 4{ }_{0}$. The ITSCCM does not contribute to the automation of the management of IT services. 
Table 13. Summation of ITS management automation items, before and after

\begin{tabular}{|l|l|l|}
\hline \multirow{2}{*}{} & \multicolumn{2}{|l|}{ SUM OF ITEMS } \\
\cline { 2 - 3 } & $\begin{array}{l}\text { BEFORE } \\
\text { (with previous mechanisms) }\end{array}$ & $\begin{array}{l}\text { BEFORE } \\
\text { (with previous mechanisms) }\end{array}$ \\
\hline TOTAL & 853 & 1265 \\
\hline MEAN & 18.54 & 27.50 \\
\hline VARIANCE & 20.698 & 16.389 \\
\hline
\end{tabular}

\subsubsection{Data (items $13,14,15,16,17$, and 18 of Appendix B)}

\subsubsection{Level of Significance}

A standard significance level of $5 \%$ was used (i.e., $\mathrm{p}<0.05$ ).

\subsubsection{Normal Distribution Check}

To check if the data were normally distributed, the Shapiro-Wilk test was applied to the difference between the "sum of items before" and the "sum of items after", obtaining the following result (Table 14).

According to Table 14, the value of the asymptotic significance was 0.178 , which was not less than 0.05 . Therefore, to estimate the p-value and carry out the corresponding hypothesis test, Student's t-test was applied.

Table 14. Normality test, automation of ITS management

\begin{tabular}{|l|l|l|}
\hline Shapiro Wilk & \multicolumn{2}{l|}{} \\
\hline Statistical & Df & Sig. \\
\hline .965 & .46 & .178 \\
\hline
\end{tabular}

\subsubsection{P-Value Estimation}

By applying Student 's t-test, the following results were obtained:

\subsubsection{Decision Making}

Based on the results shown in Tables 15 and 16, the ultimate value was below the significance level $(\mathrm{p}<0.05)$. Therefore, hypothesis $\mathrm{H} 4_{0}$ was rejected and hypothesis $\mathrm{H} 4{ }_{1}$ was accepted. Therefore, the following can be stated:

Table 15. Statistics of matched samples of ITS management automation

\begin{tabular}{|l|l|l|l|l|}
\hline & Mean & N & Standard deviation & $\begin{array}{l}\text { Standard error } \\
\text { mean }\end{array}$ \\
\hline $\begin{array}{l}\text { Part 1 } \\
\text { Total_Before }\end{array}$ & 18.54 & 46 & 4.550 & 0.671 \\
\hline Total_After & 27.50 & 46 & 4.048 & 0.597 \\
\hline
\end{tabular}


Table 16. Testing ITS management automation paired samples

\begin{tabular}{|l|l|l|l|l|l|}
\hline \multirow{2}{*}{} & \multicolumn{2}{|l|}{ Paired differences } \\
\cline { 3 - 6 } & Mean & $\begin{array}{l}\text { Standard } \\
\text { deviation }\end{array}$ & $\begin{array}{l}\text { Standard } \\
\text { error mean }\end{array}$ & \multicolumn{2}{l|}{$\begin{array}{l}\text { 95\% confidence interval of the } \\
\text { difference }\end{array}$} \\
\cline { 3 - 6 } & & & & Lower & Higher \\
\hline $\begin{array}{l}\text { Part 1. Total_Before - Total_ } \\
\text { After }\end{array}$ & -8.957 & 5.375 & .792 & -10.553 & -7.360 \\
\hline $\mathrm{t}=-11.302$ & & Df $=45$ & Sig. (bilateral $)=.000$ \\
\hline
\end{tabular}

$p=0.0000000000000097963$

The ITSCCM contributes to the automation of the management of IT services.

\section{RESEARCH LIMITATIONS}

The limitations of the study are detailed below:

In Phase 1 of the ITSCCM, the training of the model was carried out using "knowledge" of four public institutions, using approximately 1,700 records; therefore, it is necessary to continue training the model to expand this "knowledge".

The data fed into the database with which the ITSCCM was trained were in the Spanish language, as the information came from requests made by IT users who communicated in this language; therefore, for it to work with other languages, corresponding translation is required.

The precision of the model's resolutions depends on what is learnt in training; therefore, testing should continue, in order to correct possible inaccuracies and, thus, send feedback to the model.

The generation of the ITSC was carried out using an ITSRC which was created from other ITSCs found in the literature. As technology constantly evolves, the addition of new categories and services is dependent on the organization where the ITSC is initially implemented.

\section{DISCUSSION}

Accepting the limitations of the study described above, it is very important to highlight the acceptance of the four hypotheses of the researcher, in relation to which the ITSCCM contributes to the identification of ITS, classification of ITS, feedback of the ITSC, and to the automation of the ITSM. This study provides important information on what can be achieved when machine learning is applied in the ITSM; in this case, the contribution is aimed at improving the construction and management of an ITSC, with emphasis on the architecture of the catalog. For this, the evaluation carried out was pertinent, as it included IT professionals from the public sector which, according to various research related to ITSCs, has been a relegated sector for the evaluation of scientific proposals which have emerged in order to better ITSM.

The ITS identification activity is one of the most studied in the field of ITSM; however, there are few SIMs that have been evaluated from the point of view of public organizations (Mera \& Aguilar, 2019). For this reason, we considered the importance of evaluating this proposal from the point of view of IT professionals, in order to gain perspective on their perception of the implementation of tools, according to their needs.

The detailed automation within the ITSCCM can be complemented with other investigation's examples, such as that carried out by Ali (2018) with the platform that he proposed, where two of the activities carried out were the identification of the language and the translation of the language 
in the treatment of tickets (requests); this could mitigate one of the limitations of our solution, by making it able to extrapolate to other languages.

At the ITSC feedback level, our approach is based on a mechanism for the management of requests during the useful life of the catalog, providing inputs that allow reaffirmation or ruling out of ITS. However, another possibility for improvement could be given by embracing the principles established by Kalia et al. (2017), which they proposed for the management of service requests; they also focused on tasks and actions, which could not lead only to identify the category and the ITS, but also to provide possible solutions to the requirements of IT users.

\section{CONCLUSION}

At the end of this research work, the following conclusions have been reached:

The proposed ITSCCM has demonstrated positive contributions to the identification of ITS in public organizations, where automation processes allow the ITS identification task to be automated based on prior knowledge.

The contributions of the ITSCCM have been developed positively for the classification of ITS in public organizations, where classification based on an ITSRC is consolidated as a strong practice to initiate an ITSC.

The developed ITSCCM contributes positively to the feedback of the ITSC, where the automation of ITS identification makes it possible to dynamically identify the possible ITS that an IT user is requesting, such that the accumulated information can serve as feedback to the catalog itself, with the aim of confirming or discarding the ITSs present within the ITSC.

It is possible to improve the ITSM. To achieve this, one of the viable alternatives is the application of machine learning; in this case, an automatic classification system was used for the construction and management of the ITSC, focusing on the catalog architecture at the level of identification and classification of ITS and ITSC feedback in public organizations.

The applications that incorporate machine learning used by IT workers can contribute to the improvement of their work, in relation to the ITSM that an IT area or department can provide in a public organization. 


\section{REFERENCES}

Ali, A. R. (2018). Cognitive Computing to Optimize IT Services. In 2018 IEEE 17th International Conference on Cognitive Informatics Cognitive Computing (ICCI*CC) (pp. 54-60). doi:10.1109/ICCI-CC.2018.8482078

Arcilla, M., Cerrada, J. A., \& Calvo-Manzano, J. A. (2012). A practical approach for implemeting the service catalogue in micro, small and medium enterprises. 7th Iberian Conference on Information Systems and Technologies (CISTI 2012), 1-8.

Arcilla, M., Calvo-Manzano, J. A., \& San Feliu, T. (2013). Building an IT service catalog in a small company as the main input for the IT financial management. Computer Standards \& Interfaces, 36(1), 42-53. 10.1016/j. csi.2013.07.003

AXELOS. (2019). ITIL® Foundation, ITIL 4 edition (1st ed.). The Stationery Office.

Baporikar, N., \& Randa, I. O. (2020). Organizational Design for Performance Management in State-Owned Enterprises. International Journal of Service Science, Management, Engineering, and Technology, 11(4), 1-25. 10.4018/IJSSMET.2020100101

Camiola, V. D., Mascali, G., \& Romano, V. (2020). Maximum Entropy Principle. In V. D. Camiola, G. Mascali, \& V. Romano (Eds.), Charge Transport in Low Dimensional Semiconductor Structures: The Maximum Entropy Approach (pp. 29-46). Springer International Publishing. doi:10.1007/978-3-030-35993-5_2

Fischbach, M., Puschmann, T., \& Alt, R. (2013). Enhancing Soa With Service Lifecycle Management-Towards A Functional Reference Model. In ECIS 2013 Completed Research (pp. 170-182). https://aisel.aisnet.org/ ecis2013_cr/170

Flores, P., Muñoz, L., \& Sánchez, T. (2019). Estudio de potencia de pruebas de normalidad usando distribuciones desconocidas con distintos niveles de no normalidad. Revista Perfiles, 1(21), 4-11. http://dspace.espoch.edu. ec/handle/123456789/11192

Galli, B. J. (2020). Economic Decision-Making in Private Corporations Versus Public Sector: How to Compare Both Sectors. International Journal of Service Science, Management, Engineering, and Technology, 11(1), 7398. 10.4018/IJSSMET.2020010106

Gama, N., \& Rosa, M. do M., \& Silva, M. M. da. (2013). IT Services Reference Catalog. 2013 IFIP/IEEE International Symposium on Integrated Network Management (IM 2013), 764-767.

Graupner, S., Cook, N., Coleman, D., \& Nitzsche, T. (2006). Platform for Delivering IT Management Services. 2006 1st International Conference on Communication Systems Software Middleware, 1-6. doi:10.1109/ COMSWA.2006.1665212

He, K., Zhang, M., Zhou, J., Jin, Y., \& Li, C. (2020). Stochastic Item Descent Method for Large Scale Equal Circle Packing Problem. https://arxiv.org/abs/2001.08540

Huanca, J. (2018). La falsa percepción en la seguridad de los sistemas informáticos (Doctoral thesis). Universidad Nacional del Altiplano, Perú. http://repositorio.unap.edu.pe/handle/UNAP/8235

Hunnebeck, L. (2011). ITIL® Service Design (2011.a ed.). Academic Press.

Ibrahim, M., Abdallahamed, S., \& Adam, D. R. (2018). Service Recovery, Perceived Fairness, and Customer Satisfaction in the Telecoms Sector in Ghana. International Journal of Service Science, Management, Engineering, and Technology, 9(4), 73-89. 10.4018/IJSSMET.2018100105

Iden, J., \& Eikebrokk, T. R. (2017). The adoption of IT service management in the Nordic countries: Exploring regional differences. Bibsys Open Journal Systems, 25(1). https://ojs.bibsys.no/index.php/Nokobit/article/ view/395

Ishola, O. A., \& Olusoji, M. O. (2020). Service Sector Performance, Industry and Growth in Nigeria. International Journal of Service Science, Management, Engineering, and Technology, 11(1), 31-45. 10.4018/ IJSSMET.2020010103 
Jimenez, O. L., \& Garrido, G. de la C. B., \& Rodríguez, C. R. B. (2018). Comparación de clasificadores sobre mútiples datasets con pruebas estadísticas no paramétricas. Universidad\&Ciencia, 7(2), 64-82. http://revistas. unica.cu/index.php/uciencia/article/view/956

Kalia, A. K., Xiao, J., Bulut, M. F., Vukovic, M., \& Anerousis, N. (2017). Cataloger: Catalog Recommendation Service for IT Change Requests. Service-Oriented Computing. ICSOC 2017, 10601, 545-560. doi:10.1007/9783-319-69035-3_40

Khafajeh, H. (2020). An efficient intrusion detection approach using light gradient boosting. Journal of Theoretical and Applied Information Technology, 98(5), 825-835. http://www.jatit.org/volumes/Vol98No5/9Vol98No5.pdf

Lema, L., Calvo-Manzano, J.-A., Colomo-Palacios, R., \& Arcilla, M. (2015). ITIL in small to medium-sized enterprises software companies: Towards an implementation sequence. Journal of Software: Evolution and Process, 27(8), 528-538. doi:10.1002/smr.1727

Lloyd, V., \& Rudd, C. (2007). ITIL Versión 3 Service Design (2007.a ed.). Academic Press.

Marrone, M., Gacenga, F., Cater-Steel, A., \& Kolbe, L. (2014). IT Service Management: A Cross-national Study of ITIL Adoption. Communications of the Association for Information Systems, 34, 865-892. doi:10.17705/1CAIS.03449

Marrone, M., \& Kolbe, L. M. (2011). Impact of IT Service Management Frameworks on the IT Organization. Business \& Information Systems Engineering, 3(1), 5-18. doi:10.1007/s12599-010-0141-5

Mazvimavi, V., \& Benyon, R. (2009). A Theoretical Model for Developing an IT Service Catalogue. CONF-IRM 2009 Proceedings, 12. https://aisel.aisnet.org/confirm2009/12

Megahed, A., Nakamura, T., Smith, M., Asthana, S., Rose, M., Daczkowska, M., \& Gopisetty, S. (2020). Analytics and Operations Research Increases Win Rates for IBM's Information Technology Service Deals. INFORMS Journal on Applied Analytics, 50(1), 50-63. doi:10.1287/inte.2019.1023

Mera, C., \& Aguilar, I. (2018a). Review of Proposals for the Construction and Management of the Catalog of Information Technology Services (Vol. 6). IEEE Access. doi:10.1109/ACCESS.2018.2865470

Mera, C., \& Aguilar, I. (2019). Proposal for the Identification of Information Technology Services in Public Organizations. Symmetry, 11(10), 1269. doi:10.3390/sym11101269

Mera, C., \& Aguilar, I. (2018b). Field Study of the Management of the IT Services Catalog in Public Organizations in the Manabí Province, Ecuador. Proceedings of the 31st International Business Information Management Association Conference (IBIMA), 4450-4465.

Mera, C., Aguilar, I., \& Vera, D. (2020). Método para la retroalimentación del catálogo de servicios de tecnologías de la información. II Jornada Científica Ciencia, Tecnología, Innovación y Emprendimiento para el Desarrollo Sostenible de la Provincia de Manabí - Uleam Extensión Chone.

Mera, C., Aguilar, I., \& Vera, D. (2018). Evaluation of the Management of the Information Technology Services Catalog in Public Organizations in the Province of Manabí, Ecuador. Proceedings of the 2018 10th International Conference on Information Management and Engineering, 193-199. doi:10.1145/3285957.3285964

Moody, D. L., Sindre, G., Brasethvik, T., \& Solvberg, A. (2003). Evaluating the quality of information models: Empirical testing of a conceptual model quality framework. 25th International Conference on Software Engineering, 2003. Proceedings., 295-305. doi:10.1109/ICSE.2003.1201209

Motahari-Nezhad, H. R., Cappi, J. M., Nakamurra, T., \& Qiao, M. (2016). RFPCog: Linguistic-Based Identification and Mapping of Service Requirements in Request for Proposals (RFPs) to IT Service Solutions. 2016 49th Hawaii International Conference on System Sciences (HICSS), 1691-1700. doi:10.1109/HICSS.2016.213

Nissen, V., Jung, D., Petsch, M., \& Präg, C.-P. (2015). Recommendations for a general IT Service Catalogue structure. Enterprise Modelling and Information Systems Architectures, 10(1), 89-108. doi:10.18417/emisa.10.1.5

O'Loughlin, M. (2009). The service catalog-A Practitioner Guide. Academic Press.

Pilorget, L., \& Schell, T. (2018). IT Services. In IT Management: The art of managing IT based on a solid framework leveraging the company's political ecosystem (pp. 73-95). doi:10.1007/978-3-658-19309-6_4 
Rajagopal, S., Hareesha, K. S., \& Kundapur, P. P. (2020). Performance analysis of binary and multiclass models using azure machine learning. Iranian Journal of Electrical and Computer Engineering, 10(1), 978-986. doi:10.11591/ijece.v10i1.pp978-986

Rong, W., Li, T., Ouyang, Y., Li, C., \& Xiong, Z. (2014). Process Oriented Dependency Modelling for Service Identification. IFIP Advances in Information and Communication Technology, 426, 166-175. doi:10.1007/9783-642-55355-4_17

Rubio, M., \& Berlanga, V. (2012). Cómo aplicar las pruebas paramétricas bivariadas t de Student y ANOVA en SPSS. Caso práctico. REIRE, Revista d'Innovació i Recerca en Educació, 5(2), 83-100.

Sangwan, N., \& Bhatnagar, V. (2020). Comprehensive Contemplation of Probabilistic Aspects in Intelligent Analytics. International Journal of Service Science, Management, Engineering, and Technology, 11(1), 116141. 10.4018/IJSSMET.2020010108

Schorr, F., \& Hvam, L. (2018). The Use of Design-science to Define Information Content Requirements for IT Service Catalogs. 2018 IEEE International Conference on Industrial Engineering and Engineering Management (IEEM), 497-501. doi:10.1109/IEEM.2018.8607318

Shahid, M., Ahmed, A., Mushtaq, M. F., Ullah, S. M., \& Akram, U. (2020). Automatic Patents Classification Using Supervised Machine Learning. In R. Ghazali, N. M. Nawi, M. M. Deris, \& J. H. Abawajy (Eds.), Recent Advances on Soft Computing and Data Mining (pp. 297-307). Springer International Publishing. doi:10.1007/9783-030-36056-6_29

Trad, A. (2021). The Business Transformation Framework and Enterprise Architecture Framework for Managers in Business Innovation: An Applied Holistic Mathematical Model. International Journal of Service Science, Management, Engineering, and Technology, 12(1), 142-181. 10.4018/IJSSMET.20210101.oa1

Trusson, C. R., Doherty, N. F., \& Hislop, D. (2014). Knowledge sharing using IT service management tools: Conflicting discourses and incompatible practices. Information Systems Journal, 24(4), 347-371. doi:10.1111/ isj. 12025

Xu, D., Wang, Y., Tian, C., \& Qiu, X. (2010). ICT service catalogue representation method and application. 2010 IEEE 12th International Conference on Communication Technology, 1295-1298. doi:10.1109/ICCT.2010.5689074

Xu, J., Mu, J., \& Chen, G. (2020). A multi-view similarity measure framework for trouble ticket mining. Data \& Knowledge Engineering, 127. doi:10.1016/j.datak.2020.101800 


\section{APPENDICES}

\section{Appendix A. - Survey format for the assessment of IT professionals}

Objective. To determine if the proposed methodology for the construction of the ITSC based on the best practices of ITSM will contribute to the management of the catalog of IT service.

Scale used. 1 = STRONGLY DISAGREE, $2=$ DISAGREE, $3=$ NO OPINION, $4=$ AGREE, $5=$ STRONGLY AGREE.

\section{Table A1. Evaluation before using the methodology.}

\begin{tabular}{|c|c|c|c|c|c|}
\hline ISSUES & 1 & 2 & 3 & 4 & 5 \\
\hline \multicolumn{6}{|l|}{$\begin{array}{l}\text { 1. The mechanism you are currently using welcomes the request history of IT } \\
\text { users to identify IT services. }\end{array}$} \\
\hline \multicolumn{6}{|l|}{$\begin{array}{l}\text { 2. The mechanism you currently use simplifies the process of identifying IT } \\
\text { services. }\end{array}$} \\
\hline \multicolumn{6}{|l|}{$\begin{array}{l}\text { 3. The mechanism that you currently use is friendly to the IT worker to carry out } \\
\text { the process of identifying IT services. }\end{array}$} \\
\hline \multicolumn{6}{|l|}{$\begin{array}{l}\text { 4. The mechanism you currently use contributes to the process of identifying IT } \\
\text { services. }\end{array}$} \\
\hline \multicolumn{6}{|l|}{$\begin{array}{l}\text { 5. The mechanism you currently use simplifies the IT service classification } \\
\text { process. }\end{array}$} \\
\hline \multicolumn{6}{|l|}{$\begin{array}{l}\text { 6. The mechanism you currently use enables a consistent classification of IT } \\
\text { services. }\end{array}$} \\
\hline \multicolumn{6}{|l|}{$\begin{array}{l}\text { 7. The mechanism you currently use is IT worker friendly to perform the IT } \\
\text { service classification process. }\end{array}$} \\
\hline \multicolumn{6}{|l|}{$\begin{array}{l}\text { 8. The mechanism you currently use contributes to the IT service classification } \\
\text { process. }\end{array}$} \\
\hline \multicolumn{6}{|l|}{$\begin{array}{l}\text { 9. The mechanism you currently use allows you to customize the IT services } \\
\text { catalog according to the needs of the organization. }\end{array}$} \\
\hline \multicolumn{6}{|l|}{$\begin{array}{l}\text { 10. The mechanism you currently use simplifies feedback from the IT services } \\
\text { catalog. }\end{array}$} \\
\hline \multicolumn{6}{|l|}{$\begin{array}{l}\text { 11. The mechanism that you currently use is friendly to the IT worker to carry out } \\
\text { the feedback process of the IT services catalog. }\end{array}$} \\
\hline \multicolumn{6}{|l|}{$\begin{array}{l}\text { 12. The mechanism you are currently using contributes to the feedback process of } \\
\text { the IT service catalog. }\end{array}$} \\
\hline \multicolumn{6}{|l|}{$\begin{array}{l}\text { 13. The mechanism you currently use allows identification of IT services } \\
\text { automatically. }\end{array}$} \\
\hline \multicolumn{6}{|l|}{$\begin{array}{l}\text { 14. The mechanism you are currently using enables automatic classification of IT } \\
\text { services. }\end{array}$} \\
\hline \multicolumn{6}{|l|}{$\begin{array}{l}\text { 15. The mechanism you are currently using allows automatic feedback of the IT } \\
\text { services catalog }\end{array}$} \\
\hline \multicolumn{6}{|l|}{ 16. The mechanism you currently use is consistent in your automation processes } \\
\hline \multicolumn{6}{|l|}{$\begin{array}{l}\text { 17. The mechanism you currently use facilitates the management of IT services } \\
\text { through its automatic processes }\end{array}$} \\
\hline $\begin{array}{l}\text { 18. The mechanism you currently use contributes to the automation of IT service } \\
\text { management. }\end{array}$ & & & & & \\
\hline
\end{tabular}


Table A2. Evaluation after using the methodology.

\begin{tabular}{|c|c|c|c|c|}
\hline ISSUES & 2 & 3 & 4 & 5 \\
\hline \multicolumn{5}{|c|}{$\begin{array}{l}\text { 1. The proposed methodology accommodates the history of requests from IT users } \\
\text { to identify IT services. }\end{array}$} \\
\hline \multicolumn{5}{|l|}{ 2. The proposed methodology simplifies the process of identifying IT services. } \\
\hline \multicolumn{5}{|c|}{$\begin{array}{l}\text { 3. The proposed methodology is friendly to the IT worker to carry out the process } \\
\text { of identifying IT services. }\end{array}$} \\
\hline \multicolumn{5}{|l|}{$\begin{array}{l}\text { 4. The proposed methodology will contribute to the process of identifying IT } \\
\text { services. }\end{array}$} \\
\hline \multicolumn{5}{|l|}{ 5. The proposed methodology simplifies the IT service classification process. } \\
\hline \multicolumn{5}{|l|}{ 6. The proposed methodology allows a consistent classification of IT services. } \\
\hline \multicolumn{5}{|l|}{$\begin{array}{l}\text { 7. The proposed methodology is friendly to the IT worker to carry out the IT } \\
\text { service classification process. }\end{array}$} \\
\hline \multicolumn{5}{|l|}{$\begin{array}{l}8 \text {. The proposed methodology will contribute to the IT services classification } \\
\text { process. }\end{array}$} \\
\hline \multicolumn{5}{|l|}{$\begin{array}{l}\text { 9. The proposed methodology allows customizing the catalog of IT services } \\
\text { according to the needs of the organization. }\end{array}$} \\
\hline \multicolumn{5}{|l|}{ 10. The proposed methodology simplifies feedback from the IT services catalog. } \\
\hline \multicolumn{5}{|l|}{$\begin{array}{l}\text { 11. The proposed methodology is friendly to the IT worker to carry out the } \\
\text { feedback process of the IT services catalog. }\end{array}$} \\
\hline \multicolumn{5}{|l|}{$\begin{array}{l}\text { 12. The proposed methodology will contribute to the feedback process of the IT } \\
\text { services catalog. }\end{array}$} \\
\hline \multicolumn{5}{|l|}{$\begin{array}{l}\text { 13. The proposed methodology allows the identification of IT services } \\
\text { automatically. }\end{array}$} \\
\hline \multicolumn{5}{|l|}{$\begin{array}{l}\text { 14. The proposed methodology allows the classification of IT services } \\
\text { automatically. }\end{array}$} \\
\hline \multicolumn{5}{|l|}{$\begin{array}{l}\text { 15. The proposed methodology allows automatic feedback of the IT services } \\
\text { catalog }\end{array}$} \\
\hline \multicolumn{5}{|l|}{ 16. The proposed methodology is consistent in its automation processes } \\
\hline \multicolumn{5}{|c|}{$\begin{array}{l}\text { 17. The proposed methodology facilitates the management of IT services through } \\
\text { its automatic processes }\end{array}$} \\
\hline $\begin{array}{l}\text { 18. The proposed methodology will contribute to the automation of the } \\
\text { management of IT services }\end{array}$ & & & & \\
\hline
\end{tabular}




\section{Appendix B. - Data source}

Table B1. Data source.

\begin{tabular}{|c|c|c|c|c|c|c|c|c|}
\hline \multirow{3}{*}{$\begin{array}{l}\text { IT } \\
\text { STAFF }\end{array}$} & \multicolumn{8}{|c|}{ ITSM activities } \\
\hline & \multicolumn{2}{|c|}{$\begin{array}{l}\text { ITS Identification } \\
\text { Items 1, 2, 3, and } 4 \text { of } \\
\text { Appendix A }\end{array}$} & \multicolumn{2}{|c|}{$\begin{array}{l}\text { ITS Classification } \\
\text { Items } 5,6,7 \text {, and } 8 \text { of Appendix } \\
\text { A }\end{array}$} & \multicolumn{2}{|c|}{$\begin{array}{l}\text { ITSC feedback } \\
\text { Items } 9,10,11 \text {, and } 12 \text { of } \\
\text { Appendix A }\end{array}$} & \multicolumn{2}{|c|}{$\begin{array}{l}\text { ITS management automation } \\
\text { Items } 13,14,15,16,17 \text {, and } 18 \text { of } \\
\text { Appendix A }\end{array}$} \\
\hline & $\begin{array}{l}\text { BEFORE } \\
\text { (with } \\
\text { previous } \\
\text { mechanisms) }\end{array}$ & $\begin{array}{l}\text { AFTER } \\
\text { (utilizing } \\
\text { the } \\
\text { ITSCCM) }\end{array}$ & $\begin{array}{l}\text { BEFORE } \\
\text { (with previous } \\
\text { mechanisms) }\end{array}$ & $\begin{array}{l}\text { AFTER } \\
\text { (utilizing } \\
\text { the } \\
\text { ITSCCM) }\end{array}$ & $\begin{array}{l}\text { BEFORE } \\
\text { (with previous } \\
\text { mechanisms) }\end{array}$ & $\begin{array}{l}\text { AFTER } \\
\text { (utilizing } \\
\text { the } \\
\text { ITSCCM) }\end{array}$ & $\begin{array}{l}\text { BEFORE } \\
\text { (with previous } \\
\text { mechanisms) }\end{array}$ & $\begin{array}{l}\text { AFTER } \\
\text { (utilizing } \\
\text { the } \\
\text { ITSCCM) }\end{array}$ \\
\hline 1 & 16 & 19 & 16 & 19 & 15 & 18 & 18 & 26 \\
\hline 2 & 11 & 20 & 15 & 20 & 13 & 20 & 13 & 30 \\
\hline 3 & 15 & 20 & 16 & 20 & 16 & 20 & 17 & 30 \\
\hline 4 & 12 & 20 & 13 & 20 & 13 & 20 & 16 & 30 \\
\hline 5 & 20 & 20 & 18 & 20 & 18 & 20 & 24 & 30 \\
\hline 6 & 19 & 20 & 20 & 20 & 17 & 20 & 28 & 30 \\
\hline 7 & 16 & 20 & 20 & 19 & 10 & 18 & 20 & 27 \\
\hline 8 & 15 & 17 & 16 & 20 & 15 & 17 & 21 & 27 \\
\hline 9 & 13 & 20 & 13 & 20 & 15 & 20 & 27 & 30 \\
\hline 10 & 13 & 19 & 15 & 18 & 12 & 20 & 22 & 25 \\
\hline 11 & 12 & 20 & 12 & 20 & 12 & 20 & 15 & 30 \\
\hline 12 & 14 & 20 & 16 & 20 & 8 & 20 & 10 & 30 \\
\hline 13 & 12 & 18 & 12 & 17 & 12 & 18 & 14 & 27 \\
\hline 14 & 7 & 18 & 10 & 19 & 10 & 18 & 16 & 25 \\
\hline 15 & 15 & 19 & 16 & 20 & 16 & 20 & 22 & 30 \\
\hline 16 & 15 & 19 & 13 & 20 & 4 & 20 & 14 & 28 \\
\hline 17 & 13 & 20 & 13 & 20 & 7 & 20 & 13 & 30 \\
\hline 18 & 13 & 19 & 14 & 16 & 7 & 16 & 14 & 27 \\
\hline 19 & 15 & 20 & 16 & 19 & 15 & 20 & 16 & 30 \\
\hline 20 & 13 & 20 & 15 & 20 & 13 & 20 & 13 & 30 \\
\hline 21 & 13 & 15 & 16 & 15 & 16 & 16 & 15 & 23 \\
\hline 22 & 13 & 18 & 13 & 20 & 13 & 20 & 16 & 26 \\
\hline 23 & 16 & 20 & 18 & 20 & 18 & 20 & 24 & 30 \\
\hline 24 & 20 & 20 & 20 & 20 & 17 & 20 & 29 & 30 \\
\hline 25 & 16 & 19 & 20 & 19 & 10 & 19 & 20 & 29 \\
\hline 26 & 16 & 19 & 16 & 20 & 15 & 19 & 21 & 28 \\
\hline 27 & 13 & 20 & 13 & 19 & 15 & 19 & 25 & 30 \\
\hline 28 & 13 & 16 & 15 & 16 & 12 & 16 & 22 & 24 \\
\hline 29 & 12 & 5 & 12 & 5 & 12 & 5 & 15 & 6 \\
\hline 30 & 13 & 20 & 16 & 19 & 7 & 20 & 11 & 29 \\
\hline 31 & 13 & 17 & 12 & 16 & 12 & 16 & 15 & 24 \\
\hline 32 & 10 & 14 & 12 & 16 & 11 & 14 & 16 & 21 \\
\hline 33 & 11 & 19 & 15 & 20 & 16 & 20 & 22 & 24 \\
\hline
\end{tabular}


Table B1. Continued

\begin{tabular}{|c|c|c|c|c|c|c|c|c|}
\hline \multirow{3}{*}{$\begin{array}{l}\text { IT } \\
\text { STAFF }\end{array}$} & \multicolumn{8}{|c|}{ ITSM activities } \\
\hline & \multicolumn{2}{|c|}{$\begin{array}{l}\text { ITS Identification } \\
\text { Items } 1,2,3 \text {, and } 4 \text { of } \\
\text { Appendix } \mathrm{A}\end{array}$} & \multicolumn{2}{|c|}{$\begin{array}{l}\text { ITS Classification } \\
\text { Items } 5,6,7 \text {, and } 8 \text { of Appendix } \\
\text { A }\end{array}$} & \multicolumn{2}{|c|}{$\begin{array}{l}\text { ITSC feedback } \\
\text { Items } 9,10,11 \text {, and } 12 \text { of } \\
\text { Appendix A }\end{array}$} & \multicolumn{2}{|c|}{$\begin{array}{l}\text { ITS management automation } \\
\text { Items } 13,14,15,16,17 \text {, and } 18 \text { of } \\
\text { Appendix A }\end{array}$} \\
\hline & $\begin{array}{l}\text { BEFORE } \\
\text { (with } \\
\text { previous } \\
\text { mechanisms) }\end{array}$ & $\begin{array}{l}\text { AFTER } \\
\text { (utilizing } \\
\text { the } \\
\text { ITSCCM) }\end{array}$ & $\begin{array}{l}\text { BEFORE } \\
\text { (with previous } \\
\text { mechanisms) }\end{array}$ & $\begin{array}{l}\text { AFTER } \\
\text { (utilizing } \\
\text { the } \\
\text { ITSCCM) }\end{array}$ & $\begin{array}{l}\text { BEFORE } \\
\text { (with previous } \\
\text { mechanisms) }\end{array}$ & $\begin{array}{l}\text { AFTER } \\
\text { (utilizing } \\
\text { the } \\
\text { ITSCCM) }\end{array}$ & $\begin{array}{l}\text { BEFORE } \\
\text { (with previous } \\
\text { mechanisms) }\end{array}$ & $\begin{array}{l}\text { AFTER } \\
\text { (utilizing } \\
\text { the } \\
\text { ITSCCM) }\end{array}$ \\
\hline 34 & 15 & 18 & 13 & 19 & 6 & 16 & 15 & 28 \\
\hline 35 & 15 & 16 & 13 & 17 & 11 & 16 & 14 & 25 \\
\hline 36 & 13 & 16 & 13 & 16 & 11 & 16 & 15 & 24 \\
\hline 37 & 13 & 20 & 13 & 20 & 15 & 20 & 23 & 30 \\
\hline 38 & 13 & 19 & 15 & 20 & 12 & 20 & 20 & 30 \\
\hline 39 & 13 & 20 & 12 & 20 & 12 & 20 & 21 & 27 \\
\hline 40 & 13 & 20 & 16 & 20 & 11 & 20 & 22 & 30 \\
\hline 41 & 10 & 20 & 12 & 20 & 12 & 20 & 18 & 30 \\
\hline 42 & 11 & 20 & 12 & 20 & 11 & 20 & 21 & 30 \\
\hline 43 & 15 & 17 & 16 & 18 & 15 & 19 & 18 & 29 \\
\hline 44 & 13 & 20 & 13 & 20 & 8 & 20 & 17 & 28 \\
\hline 45 & 13 & 19 & 14 & 14 & 12 & 18 & 23 & 28 \\
\hline 46 & 13 & 20 & 13 & 20 & 12 & 20 & 22 & 30 \\
\hline
\end{tabular}

Igor Aguilar Alonso currently is researcher professor at Universidad Tecnológica de Lima Sur - UNTELS, and professor at undergraduate and graduate courses at the School of Systems and Computer Engineering, Universidad Nacional Mayor de San Marcos - UNMSM, Peru. He received his PhD from the Universidad Politécnica de Madrid - UPM, Spain in 2013. His areas of research are: IT Governance, IT Services Management, IT Innovation Management and Business. His research papers have been presented at conferences and published in journals internationally. Dr. Aguilar is a reviewer member of the National Council for Science and Technology (CONCYTEC) in Peru, and is serving as a referee of research for national and international scientific journals, and conference proceedings. He also worked as an employee at IBM Global Service, Spain. 